\title{
EPIDEMIOLOGY OF BLINDING EYE DISEASES IN CROSS RIVER STATE, NIGERIAAS SEEN IN UNIVERSITY OF CALABAR TEACHING HOSPITAL
}

\author{
BY \\ EKPENYONG, B. N. \\ DEPARTMENT OF OPHTHALMOLOGY, \\ UNIVERSITY OF CALABAR \\ CROSS RIVER STATE NIGERIA \\ Email: benyital2001@yahoo.com
}

\begin{abstract}
This study was to determine the magnitude and distribution of blinding eye diseases in Cross River State. A total of 3903 case files of patients who visited the University of Calabar Teaching Hospital (UCTH) from January 2001-September 2003 were reviewed. Secondly 580 patients who visited the hospital within 3 months of the study period October 2003- December 2003 were examined and questionnaires administered on them. The overall prevalence of blindness during the study period was 9.2\%. Cataract caused blindness in nearly half of the cases. Other important causes of blindness include refractive error, glaucoma, retinal/macular diseases and corneal diseases. The overall prevalence of these identified blinding eye diseases was $56.3 \%$. Refractive error $(62.8 \%)$ was the most prevalent followed by cataract (15.4\%), glaucoma (11\%), retinal/macular diseases $(7 \%)$ and corneal disease $(3.7 \%)$. Results of analysis have shown that the prevalence of blinding eye diseases depends on age, sex and occupation. Increasing age and being male characterized the prevalence of cataract, glaucoma and retinal/macular diseases. More females were seen to have refractive error while more males and children had corneal diseases. The prevalence of blinding eye diseases was also seen more among people that do out door jobs.
\end{abstract}

KEYWORD: Epidemiology, Prevalence, Blinding eye diseases, Refractive error, Cataract.

\section{INTRODUCTION}

Blindness is an increasing global health problem that afflicts approximately 50 million people, two-thirds of whom are women and ninety percent of whom live in poorer countries. There are at least 1.3 million blind Nigerians. About $80 \%$ of the causes of blindness in Nigeria are avoidable (preventable or curable), yet each year 200,000 more Nigerians add to the blind population. The chief causes of blindness in Nigeria include cataract, glaucoma, trachoma and onchocerciasis ${ }^{1}$.

Prevalence of eye diseases, apart from varying from place to place, also depend on the age group, sex and occupation and its magnitude is calculated based on blindness rate. The pattern and rate of blinding disorders is different in developed and developing nations depending on whether nutritional and infectious causes of blindness are eradicated, and whether there are resources available for treatable disorder such as cataract and refractive errors. Competing demands from life threatening diseases such as AIDS and malaria are pushing eye health services further down the agenda list of public health priorities. It has therefore become necessary for some information to be provided on the epidemiology of blinding eye diseases in order to plan adequately for eye care services.

\section{MATERIALS AND METHOD}

The study was carried out in the University of Calabar Teaching Hospital (UCTH) Cross River State, Nigeria. It is the only centre that provides tertiary eye care services in the state. The data from the study was collected using an abstract form to collect information on all patients seen at the eye clinic of UCTH, Calabar. This was done in 2 stages.

In first stage, case records of all patients seen at the eye clinic from January 2001- September 2003 were reviewed. Information concerning patient demographic data, history, place of residence, occupation, presenting complaint, duration of complaint and clinical finding/diagnosis were extracted from the case files. In the second stage, all new patients seen in the eye clinic between October ï December 2003 were interviewed through a questionnaire and screened for diagnosis. Visual acuity (VA) at distant and near, was done using the tumbling E-chart, external eye examination, refraction, tonometry, funduscopy and confrontational visual field examination were carried out on the entire visiting patient. The findings were recorded in section $\mathrm{B}$ of the 
questionnaire.

Causes of eye diseases were classified by etiology and by site of affection. Blindness was defined as presenting VA of 3/60 on the better eye. Treatment administered, result of treatment and follow up was not presented, since they are beyond the scope of the study.

The data generated were classified and analyzed using analysis of variance (ANOVA) and Chi-Square. In testing the association between sex, occupation and the prevalence of blinding eye disease, the Chi-Square test was used, while ANOVA was applied to find the association between age and the prevalence of blinding eye diseases.

\section{RESULTS}

A total of 4,483 patients were seen in the hospital within the three years period. There were $2355(52 \%)$ females and 2128 (48\%) males as shown in Table 1. Four hundred and fourteen (9.2\%) were blind (presenting VA $<3 / 60$ on the better eye). Ninety four per cent of all patients examined were resident in Cross River State, $4.8 \%$ in Akwa Ibom State, 0.9\% in Igbo speaking States and others $0.2 \%$ as shown in Table 2 .

The blinding eye diseases, as identified in this study are as shown in Table 3. Cataract was seen as the leading cause o blindness, causing 165 (40\%) of blindness. Of the 398 cataract cases seen, 165 were blind due to cataract, while $103(26.1 \%)$ were blind due to refractive error from the 1,582 refractive error cases. There are $84(20.3 \%)$ blind glaucoma patients from the 278 cases of glaucoma, and $42(10.2 \%)$ blind of the 177 cases of retinal/macular diseases. Twenty patients $(4.8 \%)$ were blind from corneal opacity out of 93 with corneal diseases.

The prevalence of blinding eye disease in this study was $56.2 \%$, meaning that 2,519 person had eye conditions that can lead to bilateral blindness. One thousand two hundred and sixty five $(50.2 \%)$ were females while $1,254(49.8 \%)$ were males. Refractive error was the most prevalent, accounting for $1,582(62.8 \%)$, while cataract accounted for 389 (15.4\%). Glaucoma patients were $278(11 \%)$, while $177(7.0 \%)$ had retinal /macular disease and 93 (3.7\%) had corneal disease (see table 3). The balance of 1,964 patients of 4,483 cases had other eye conditions that did not cause bilateral blindness in the study.

Table 4 shows the age and sex distribution of all the blinding eye diseases seen. Refractive error was more prevalent among the females, accounting for 877 (55.4\%) while 705 (44.6\%) were males. Cataract on the other hand was seen to be more common among males and the elderly, $55 \%$ (210) were males and $44.5 \%$ (173) were females. Patients from 50 years and above constituted $71 \%$ of those with cataract. The sex distribution has shown that $172(61.9 \%)$ of those with glaucoma were males while $106(38.1 \%)$ were females. Glaucoma was also found to have occurred more in those 30 years and above as shown in table 4.

Corneal diseases were seen to have occurred more in males and children. The males were 59 $(63.4 \%)$, and females 34 (36.6\%). About $64 \%$ of those with corneal problem were between 0 29years. Retinal/macular diseases were seen to be more prevalent in males and the elderly, $102(57.6 \%)$ males and $75(42.3 \%)$ females.

The relationship between occupation and prevalence of blinding diseases is as shown in table 5. In the table, $569(36.1 \%)$ of those with refractive error were professionals, followed by pupils/students $559(35.4 \%)$ and non-professional $450(28.5 \%)$. Those who were non-professional accounted for $263(67 \%)$ and pupils/students 23 $(5.9 \%)$. Those with glaucoma, $124(45 \%)$ were non-professionals; professional were $102(26.3 \%)$, while pupils/students were $50(18 \%)$. The prevalence of retinal/macular diseases by occupations showed that $80(45.2 \%)$ were professionals; $73(41.2 \%)$ non-professionals and pupils/students $24(13.6 \%)$. Pupils/students accounted for $44(47.3 \%)$ of those with corneal diseases, non-professionals $31(33.3 \%)$ and professionals $18(19.4 \%)$.

\section{DISCUSSION}

The result of this study provides the first measure of the prevalence of blinding eye diseases in Cross River State. Five causes of blindness were identified in this study, and they include cataract, refractive error, glaucoma, retinal/macular diseases and corneal opacity/scar. These eye conditions caused blindness to $414(9.2 \%)$ patients of the population studied. This is high compared to a previous UCTH based blindness study ${ }^{2}$. This difference could be attributed to lack of eye care services or due to difference in the blindness definition used in the two studies. The prevalence of blindness in the North Eastern Taraba State of Nigeria was $11.8 \%$ while another $16.1 \%$ had visual impairment. Umeh found $5.4 \%$ in Southern Nigeria ${ }^{4}$. 
The study emphasis was on all the identified cases of blinding eye disease not just the blind cases, presented in the UCTH eye clinic within a 3year period, (2001-2003). The prevalence of blinding eye diseases in Cross River State as seen in UCTH was found to be $56.2 \%$. Refractive error was seen as the most prevalent, followed by cataract, glaucoma, retinal/macular diseases and corneal diseases. These results are similar to the findings of studies carried out in Nigeria ${ }^{5,6,7,8}$.

The association of blinding eye diseases with age, sex and occupation remained statistically significant. Cataract was the most important cause of blindness in Cross River State, causing about $40 \%$ of blindness. It was also seen to be the second most prevalent blinding eye disease in the study area. The prevalence of cataract was higher among males than females. These results are inconsonance with similar studies in Nigeria ${ }^{8,9,10}$. The study in Zambia also found that men (43\%) were more affected by cataract than women $(38 \%)^{11}$. This finding suggests that the men in this part of the world are more involved in outdoor work and activities than the women which exposes them to sunlight and UV rays (important risk factor to cataract formation). However, this result is contrary to reports from different surveys carried out in the developed countries, which indicates that women are about 10-15\% more likely to develop cataract than men ${ }^{12,13}$. Reason was that the prevalence in women increases with number of children reproductive and/or hormonal factor may play role. The study also revealed that cataract was more common among the elderly, from 50years and above that do outdoor jobs. A similar trend was found in numerous other studies undertaken in both industrialized and developing countries ${ }^{8,13,14,15}$.

Refractive error was found to be the most prevalent blinding eye and the second important cause of blindness in Cross River. This finding is only consistent with studies that used presenting visual acuity instead of corrected visual acuity as the working definition of blindness. A study on the causes and profile of visual loss in an onchocerciasis-endemic forest-Savanna zone in Nigeria showed refractive error as the number one cause of visual loss ${ }^{12}$. In Australia, 33\% of the blind was as a result of uncorrected refractive error ${ }^{16}$. In Zambia, refractive error caused $8 \%$ of blindness ${ }^{11}$. The study also revealed that refractive error occurred more in females and also occurred in children, but the problem with near vision was even more marked especially in the elderly. These findings are similar to some studies carried out within and outside the country ${ }^{8,11,16}$. Refractive error was more in professionals and pupil/students, those who do a lot of reading and near work.

Results of the study showed that glaucoma is the third most prevalent blinding eye disease in Cross River State. It caused $20.3 \%$ of blindness. This compares with $25 \%$ recorded by Ezepue ${ }^{9}$ and $20 \%$ recorded by Olurin ${ }^{6}$. Potter ${ }^{17}$ found glaucoma to be the cause in $12.7 \%$ of bilaterally blind attending eye clinics. Glaucoma was found to occur most in men in this study and the prevalence was found to increase with age especially from $30 y e a r s$ and above. This finding agrees with other studies carried out within and outside the country ${ }^{2,8,9}$. The prevalence of glaucoma by occupation was seen to occur more among nonprofessionals than professionals and pupils/students.

The forth important cause of blindness recorded is retinal/macular diseases, the prevalence increases with age, occurred more in male 40years and above. The common form of retinal/macular diseases recorded in this study includes age related macular diseases recorded in this study includes age related macular degeneration, diabetic retinopathy and optic atrophy. The study has also shown that $45.2 \%$ of those with retinal/macular disease were professionals.

The prevalence of corneal disease in this study was found to occur mostly in males and children, about $50 \%$ of those with corneal disease were pupils and students. Infection is one of the important causes of corneal opacity in children usually as a result of vitamin Adeficiency, measles infection and conjunctivitis of the newborn. Harmful traditional eye medication and trauma were other important recorded causes of corneal opacity in the study area.

The prevalence of blindness and blinding eye diseases are relatively high. It is therefore important that plan to provide comprehensive and sustainable eye care services be made for the communities in Cross River State, based on community participation in line with Vision 2020 objectives.

\section{Acknowledgement}

I acknowledge the contributions of Dr. B. M. Ikpeme (my supervisor), Professor E. I. Braide, Dr. U. Asana, Dr. E. E. Chukwu and DR. B. Ndubueze. 
TABLE 1: AGE AND SEX DISTRIBUTION OF PATIENT VISITING UCTH EYE CARE JAN 2001-DEC 2003.

\begin{tabular}{|l|l|l|ll|}
\hline Age & Male & Female & Total \% \\
\hline 0 ï 9 & 214 & 187 & $401 \quad(8.9)$ \\
\hline 10 ï 19 & 253 & 435 & $688 \quad(15.3)$ \\
\hline 20 ï 29 & 394 & 685 & $1079 \quad(24.1)$ \\
\hline 30 ï 39 & 395 & 361 & $756 \quad(16.9)$ \\
\hline 40 ï 49 & 400 & 300 & $700 \quad(15.6)$ \\
\hline 50 ï 59 & 236 & 176 & $412 \quad(9.2)$ \\
\hline $60+$ & 236 & 211 & $447 \quad(10.0)$ \\
\hline Total & $2128(48 \%)$ & $2355(52 \%)$ & $4483 \quad(100)$ \\
\hline
\end{tabular}

TABLE 2: DISTRIBUTION OF PATIENTS BY PLACE OF RESIDENCE

\begin{tabular}{|l|l|}
\hline Place of Residence & No of Patients (\%) \\
\hline Cross River State & 94.1 \\
\hline Akwa Ibom & 4.8 \\
\hline Igbo Speaking States & 0.9 \\
\hline Others & 0.2 \\
\hline
\end{tabular}

TABLE 3: MAGNITUDE OF BLINDING EYE DISEASES IN CROSS RIVER STATE

\begin{tabular}{|l|l|l|}
\hline Cause/Blinding eye disease & No of Class & Number Blind \\
\hline Cataract & $389(62.8 \%)$ & $165(39.9 \%)$ \\
\hline Refractive error & $1582(15.4 \%)$ & $103(26.1 \%)$ \\
\hline Glaucoma & $278(11.0 \%)$ & $84(20.3 \%)$ \\
\hline Retinal/macular diseases & $177(7.0 \%)$ & $42(10.2 \%)$ \\
\hline Corneal diseases & $93(3.7 \%)$ & $20(4.8 \%)$ \\
\hline Total & $2519(100 \%)$ & $414(100 \%)$ \\
\hline
\end{tabular}

TABLE 4: AGE AND SEX DISTRIBUTION OF PATIENTS WITH BLINDING EYE DISEASES

\begin{tabular}{|l|l|l|l|l|l|l|}
\hline Age & $\begin{array}{l}\text { Ref. error } \\
(\%)\end{array}$ & Cataract (\%) & $\begin{array}{l}\text { Glaucoma } \\
(\%)\end{array}$ & $\begin{array}{l}\text { Retinal/macula } \\
\text { r Diseases (\%) }\end{array}$ & $\begin{array}{l}\text { Corneal } \\
\text { Diseases (\%) }\end{array}$ & Total (\%) \\
\hline $0-9$ & $55(3.5)$ & $8(2.1)$ & $4(1.4)$ & $3(1.7)$ & $23(24.7)$ & $\mathbf{9 3 ( 3 . 7 )}$ \\
\hline $10-19$ & $239(15.1)$ & $13(3.3)$ & $21(7.5)$ & $6(3.4)$ & $10(10.8)$ & $289(11.5)$ \\
\hline $20-29$ & $364(23)$ & $16(4.1)$ & $39(14.0)$ & $20(11.3)$ & $26(28.0)$ & $465(18.5)$ \\
\hline $30-39$ & $301(19)$ & $23(5.9)$ & $38(13.7)$ & $25(14.1)$ & $16(17.2)$ & $403(16.0)$ \\
\hline $40-49$ & $351(22.2)$ & $49(12.6)$ & $46(16.5)$ & $40(22.6)$ & $12(12.9)$ & $498(19.8$ \\
\hline $50-59$ & $170(10.7)$ & $94(24.2)$ & $54(19.4)$ & $33(18.6)$ & $3(3.2)$ & $354(14.1)$ \\
\hline $60+$ & $102(6.4)$ & $186(47.8)$ & $76(27.3)$ & $50(28.2)$ & $3(3.2)$ & $417(16.6)$ \\
\hline Total (\%) & M:705(44.6) & M:216(55.5) & M: $172(61.9)$ & M: $102(57.6)$ & M:59(63.4) & M:1254(49.8) \\
& F:877 (55.4) & F:173(44.4) & F: $106(38.1)$ & F: $75(42.4)$ & $\begin{array}{l}\text { F:34 (36.6) } \\
93(3.7)\end{array}$ & $\begin{array}{l}\text { F: } 1265(50.2) \\
2519(100)\end{array}$ \\
\hline
\end{tabular}

TABLE 5: PREVALE NCE OF BLINDING EYE DISEASES BY OCCUPATION

\begin{tabular}{|l|l|l|l|l|l|l|}
\hline Occupation & Ref. error (\%) & $\begin{array}{l}\text { Cataract } \\
\mathbf{( \% )}\end{array}$ & $\begin{array}{l}\text { Glaucoma } \\
\mathbf{( \% )}\end{array}$ & $\begin{array}{l}\text { Retinal/ } \\
\text { macular diseases (\%) }\end{array}$ & $\begin{array}{l}\text { Corneal } \\
\text { Diseases (\%) }\end{array}$ & Total (\%) \\
\hline Pupi//Std & $559(35.4)$ & $23(5.9)$ & $50(18.0)$ & $24(13.6)$ & $44(47.3)$ & $700(27.9)$ \\
\hline Professional & $569(36.1)$ & $102(26.3)$ & $104(37.4)$ & $80(45.2)$ & $18(19.4)$ & $873(34.7)$ \\
\hline $\begin{array}{l}\text { Non- } \\
\text { Professional }\end{array}$ & $450(28.5)$ & $263(67.0)$ & $124(45.0)$ & $73(41.2)$ & $31(33.3)$ & $941(37.4)$ \\
\hline Total (\%) & 1474 & 388 & 278 & 177 & 93 & $2514(100)$ \\
\hline
\end{tabular}




\section{R E F E R E N C E S}

1. Apiafi, D. I. (2001): The status of blindness and blindness prevention in Nigeria. Paper presented during SSI stakeholders' workshop on Kwara State Eye Care $18^{\text {th }}-22^{\text {nd }}$ Nov. 2001. (Unpublished).

2. Asana, U. E., Malaki, A. and Ajen, F. M. O. (1994): Programme of prevention of blindness in Cross River State of Nigeria: Progress report. Nig. J. Ophthalmol, 2(2):74-80.

3. Akogun, O. B. (1992): Eye lesions, blindness and visual impairment in the Taraba river valley, Nigeria and their relation to onchocercal microfilariae in skin. Acta Trop, 51 (2): 143-9.

4. Umeh, R. E. (1999): The causes and profile of visual loss in an onchocerciasis endemic forest-Savanna zone in Nigeria. Ophthalmic Epidemiol, 126(4): 303-18.

5. Akinsola, F. B. (1993): Pattern of eye diseases in Nigerian children seen at Lagos University Teaching Hospital. Nig. Med. Pract, 25(4):4753.

6. Olurin, O. (1970): Aetiology of blindness in Nigerian children. Am. J. Ophthalmol, 70:53340.

7. Olurin, O. (1973): Causes of blindness in Nigeria-a study of 1,000 hospital patients. West Afri. Med. J, 22 (6):97-107.

8. Tarilah, T. (1995): Pattern of eye diseases in Port-Harcourt and an oil producing rural community. Nig. J. Ophthalmol, 6-10.

9. Ezepue, F. U. (1989): Causes of blindness as seen in the eye clinic of the University of Nigeria Teaching Enugu. Unpublished Thesis Report.

10. Adeoye, A. (1996): Survey of blindness in rural communities of South-Eastern Nigeria. Trop. Med. Int. Hlth, 1(5): 672-6.

11. Lan, Y. and Boateng, W. (2002): An outreach eye care programme in Zambia. Com. Eye Hlth. J, 15(41): 13-4.

12. Klein, B. E., Klein, R. and Moss, B. E. (1997): Incident cataract Surgery: the Beaver Dam Eye study. Ophthalmol, 104: 573-80.

13. Hiller, R., Sperduto, R. D. and Ederer, F. (1983): Epidemiological association with cataracts in 1971-1972 National Health and Nutrition Examination Survey. Am. J. Epidemiol, 118:239-49.

14. Faal, H., Minassian, D., Sowa, S. and Foster, A. (1989): National survey of blindness and low vision in the Gambia. Br. J. Ophthalmol, 73:827.

15. Ezepue, F. U. (1997): Magnitude and causes of blindness and low vision in Anambra State of Nigeria (Results of 1992 point prevalence survey). Pub. Hlth, 111(5): 305-404.

16. Hugh, R. T. (2000): Refractive errors: Magnitude of the need. Com. Eye Hlth. J, 13(33):1-2.

17. Potter, A. R. (1991): Causes of blindness and visual handicap in the Central African Republic Br. J. Ophthalmol, 75:326-8. 